\title{
MicroRNA-497 attenuates cerebral infarction in patients via the TLR4 and CREB signaling pathways
}

\author{
SI CHEN, WENWEI YIN, KUN BI and BIN LU \\ Department of First Neurosurgery, Tangshan Worker Hospital, Tangshan, Hebei 063000, P.R. China
}

Received November 7, 2016; Accepted March 1, 2018

DOI: 10.3892/ijmm.2018.3611

\begin{abstract}
The aim of the present study was to investigate the function and mechanism of microRNA-497 (miRNA/miR-149) in the regulation of cerebral infarction. In patients with cerebral infarction, the serum of microRNA-497 expression was upregulated compared with that in healthy controls. In N2A cells, overexpression of miR-497 induced cell proliferation, decreased apoptosis and caspase- 3 and caspase- 9 activities, and suppressed Bax protein expression compared with that in the negative control group. Overexpression of miR-497 reduced inflammation factors, and suppressed the Toll-like receptor 4 (TLR4), myeloid differentiation primary response protein MyD88 (MyD88) and nuclear factor- $\kappa \mathrm{B}(\mathrm{NF}-\kappa \mathrm{B})$ protein expression of the $\mathrm{N} 2 \mathrm{~A}$ cells. Next, miR-497 overexpression suppressed the protein expression of interleukin-1 receptor associated kinase (IRAK1) and phosphorylated cyclic AMP response element binding protein (p-CREB) in the N2A cells. Following miR-497 overexpression, TLR4 inhibitor was found to suppress the inflammation factors, suppress the TLR4, MyD88 and NF- $\kappa \mathrm{B}$ protein expression, and reduce the IRAK1 and $\mathrm{p}-\mathrm{CREB}$ protein expression of the N2A cells. Lastly, CREB inhibitor also suppressed p-CREB protein expression, induced cell proliferation, decreased apoptosis and caspase- 3 and caspase- 9 activities, and suppressed Bax protein expression in the N2A cells following miR-497 overexpression. Taken together, these data demonstrated that miR-497 attenuated cerebral infarction in patients by regulating the TLR4 and CREB signaling pathways.
\end{abstract}

\section{Introduction}

Cerebrovascular disease is one of the main diseases that threaten human health, and it ranks the top among the three major causes of mortality in China, with ischemic cerebrovascular disease, a

Correspondence to: $\mathrm{Mr}$. $\mathrm{Si}$ Chen, Department of First Neurosurgery, Tangshan Worker Hospital, 27 Wenhua Road, Tangshan, Hebei 063000, P.R. China

E-mail: 41565480@qq.com

Key words: microRNA-497, cerebral infarction, Toll-like receptor 4, cyclic AMP response element binding protein common and frequently occurring disease that causes mortality and disability, accounting for $60-80 \%$ (1). At present, early thrombolytic therapy is applied for ischemic cerebrovascular disease so as to restore the local blood supply; however, the resulting reperfusion will aggravate the further injury of the ischemic tissue $(2,3)$. As a result, there is an urgent requirement to search for an effective drug for treating ischemia- and reperfusion-induced brain injury.

Brain anoxia and ischemia subsequent to cerebral infarction will result in a series of pathophysiological processes (4). The neurons, glial cells and vascular endothelial cells will develop edema, necrosis and apoptosis as a result of the lack of nutrient and energy supply, as well as the inability to discharge metabolic waste, accompanied with inflammatory factor release, cascade amplification, and free radical and calcium ion overload (5). During this process, a series of molecules, including nucleic acids and proteins, will acquire profound changes, which will aggravate or improve the pathological process of cerebral infarction, while their mutual equilibrium and development will influence the outcome and prognosis for cerebral infarction (6).

The cerebral infarction is a complicated pathophysiological process: Firstly, the growth factor receptor, which can promote angiogenesis on the vascular endothelial cell, is activated together with the relevant enzymes in the body; secondly, the activated vascular endothelial cell begins to release metalloprotease so as to degrade the basilar membrane; thirdly, the vascular endothelial cell migrates to the corresponding position, secretes and forms the surrounding matrix, and proliferates into the budding structure, which continues to enlarge and form the annular tube cavity; and finally, the perivascular cell, smooth muscle cell and astrocyte proliferate, migrate, differentiate, and occlude to form the mature vascular cavity $(7,8)$.

MicroRNAs (miRNAs/miRs), a type of endogenous non-coding RNA discovered in eukaryotes, has regulatory functions, and the mature miRNAs have 20-25 nucleotides. miRNA binds with the 3'-terminal non-coding domain of a specific target gene and forms the silencing complex, which will inhibit the translation of the target mRNA or promote the degradation of the mRNA, thus exerting its biological functions (9). As has been previously demonstrated, miRNAs regulate angiogenesis under physiological and pathological conditions through regulation of the key molecules of angiogenesis (10). 
Toll-like receptor (TLR) was first identified in fruit flies, and it was named since its extra-cellular fragment was homologous to a type of fruit fly protein Toll (11). The TLR family is a signal energy transformation molecular family, which serves a key role in the immune response and inflammatory response (11). TLR is a type of transmembrane receptor that is mainly distributed in immune cells and on the cavitary epithelial cell surface, and can identify various pathogen-associated molecular patterns, induce the inherent immune response of the body, induce a series of gene activations through various signal transduction pathways, promote increased inflammatory cytokine secretion and cause a systemic inflammatory response (12).

Attention has been paid to the roles of TLR4 ligands myeloid differentiation primary response protein MyD88 (MyD88) and Toll/interleukin-1 receptor domain-containing adapter protein (TIRAP), as well as the negative feedback protein that gradually influences the TLR signal transduction pathway, Toll-interacting protein, in cerebral infarction. Recently, there has been increasing evidence of the TLR4-TIRAP-MyD88 signal pathway $(13,14)$.

The active cyclic AMP response element binding protein (CREB) participates in multiple processes, including neuro-development, synaptic plasticity, memory function, regeneration and cell survival, so as to cope with all manner of stimulations, such as ischemia (15). Since 1990, phosphorylated (p-)CREB has been extensively researched in multiple ischemic models, and its downstream neuroprotection targets include apoptosis regulator $\mathrm{Bcl}-2(\mathrm{Bcl}-2)$ and brain-derived neurotrophic factor (BDNF), and thus promote the survival of the ischemic neurons (16). The present study investigated the role and mechanism of miR-497 to regulate cerebral infarction.

\section{Materials and methods}

Clinical specimens. Male patients with cerebral infarction $(n=6 ; 55-62$ years old $)$ and healthy volunteers $(n=4 ; 57-65$ years old) from Tangshan Worker Hospital (Tangshan, Hebei, China) were enrolled in the present study between October 2015 and March 2016. All patients provided written informed consent and the study was approved by the Medical Ethics Committee of Tangshan Worker Hospital. Whole blood was collected and centrifuged at $1,000 \times \mathrm{g}$ for $10 \mathrm{~min}$ at room temperature. Serum was stored at $-80^{\circ} \mathrm{C}$ for further experiments.

Reverse transcription-quantitative polymerase chain reaction (RT-qPCR) analyses. The total RNA of every serum sample was isolated using TRIzol reagent (Invitrogen; Thermo Fisher Scientific, Inc., Waltham, MA, USA) according to the manufacturer's protocols. cDNA was reverse transcribed from 20-50 ng total RNA using the miRCURY LNA ${ }^{\mathrm{TM}}$ Universal RT microRNA PCR (Invitrogen; Thermo Fisher Scientific, Inc.). cDNA $(1 \mu \mathrm{l})$ was used for RT-qPCR (CFX-96 PCR machine; Bio-Rad Laboratories, Inc., Hercules, CA, USA) with the SYBR-Green Supermix (Invitrogen; Thermo Fisher Scientific, Inc.). RT-qPCR was performed at $95^{\circ} \mathrm{C}$ for $5 \mathrm{~min}$, followed by 40 cycles of $95^{\circ} \mathrm{C}$ for $30 \mathrm{sec}, 60^{\circ} \mathrm{C}$ for $30 \mathrm{sec}$ and $70^{\circ} \mathrm{C}$ for $20 \mathrm{sec}$. miR-497 expression was quantificated using $2^{-\Delta \Delta \mathrm{Ct}}(17)$.

Cell culture, transfection and ischemic injury of N2A cells. Mouse N2A cells were obtained from the Cell Culture
Center of Chinese Peking Union Medical College (Beijing, China) and cultivated in Dulbecco's modified Eagle's medium (DMEM; Gibco; Thermo Fisher Scientific, Inc.) containing $10 \%$ fetal bovine serum, in a $5 \% \mathrm{CO}_{2} / 95 \% \mathrm{O}_{2}$ atmosphere at $37^{\circ} \mathrm{C}$. N2A cells were transfected with miR-497 (100 ng; 5'-CCACCCCGGTCCTGCTCCCG-3' and 5'-GGTGGGGGAGGCACCGCCGAGG-3') and negative vector (Sangon Biotech Shanghai Co., Ltd., Shanghai, China) using Lipofectamine $2000^{\circledR}$ (Invitrogen; Thermo Fisher Scientific, Inc.). Following transfection for 24 h, N2A cells were replaced by glucose-free DMEM (Gibco; Thermo Fisher Scientific, Inc.) and $50 \mathrm{ng} / \mathrm{ml} \mathrm{LPS}$ in a hypoxic chamber $\left(5 \% \mathrm{CO}_{2}, 1 \% \mathrm{O}_{2}\right.$ and $94 \% \mathrm{~N}_{2}$ ) for $4 \mathrm{~h}$, and then under normoxic conditions for $24 \mathrm{~h}$. TLR4 inhibitor (TAK-242, 2-5 $\mu \mathrm{M}$ ) was added to the N2A cells for $4 \mathrm{~h}$. CREB inhibitor $(666-15,5 \mu \mathrm{M})$ was added to the N2A cells for $12 \mathrm{~h}$.

3-(4,5-Dimethylthiazol-2-yl)-2,5-diphenyltetrazolium bromide (MTT) assay. N2A cells were seeded in 96-well plates at a density of $2 \times 10^{4}$ cells/well and incubated with MTT $(0.5 \mathrm{mg} / \mathrm{ml})$ for $3 \mathrm{~h}$. The medium was removed from each well and dimethyl sulfoxide (100 $\mu \mathrm{l})$ was added. Absorbance was measured using an Infinite M200 PRO Multimode Microplate (Tecan Group, Ltd., Mannedorf, Switzerland) at $492 \mathrm{~nm}$.

Apoptosis assay. N2A cells were seeded in 6-well plates at a density of $2 \times 10^{6}$ cells/well and incubated with Annexin V-fluorescein isothiocyanate and propidium iodide (Bio-Rad Laboratories, Inc.) at $25^{\circ} \mathrm{C}$ for $5-15 \mathrm{~min}$ (in the dark). The total number of apoptotic cells was quantified by a flow cytometer (BRYTE HS; Bio-Rad Laboratories, Inc.) and FlowJo 7.6 (Tree Star, Inc., Ashland, OR, USA).

Measurement of inflammation factors. Total protein was isolated from the N2A cells with an ice-cold cell lysis reagent (FNN0091; Thermo Fisher Scientific, Inc., Rockford, IL, USA) according to the manufacturer's protocols. The protein concentration was measured using the Pierce bicinchoninic acid assay (BCA) reagent (Thermo Fisher Scientific, Inc.). Proteins (5 $\mu \mathrm{g})$ were incubated with enzyme-linked immunosorbent assay (ELISA) kits [interleukin (IL)-1 $\beta$ (H002), IL-6 (H007) and IL-8 (H008); Nanjing Jiangcheng Bioengineering Institute, Nanjing, China]. Absorbance was measured using Infinite M200 PRO Multimode Microplate (Tecan Group, Ltd.) at $450 \mathrm{~nm}$.

Caspase-3/9 activity assay. Total protein was isolated from N2A cells with an ice-cold cell lysis reagent (FNN0091; Thermo Fisher Scientific, Inc.) according to the manufacturer's protocols. The protein concentration was measured using the Pierce BCA reagent (Thermo Fisher Scientific, Inc.). Proteins $(5 \mu \mathrm{g})$ were incubated with caspase-3/9 activity kits (Bio-Rad Laboratories, Inc.). Absorbance was measured using Infinite M200 PRO Multimode Microplate (Tecan Group, Ltd.) at $405 \mathrm{~nm}$.

Western blot analysis. Total protein was isolated from N2A cells with an ice-cold cell lysis reagent (FNN0091; Thermo Fisher Scientific, Inc.) according to the manufacturer's protocols. The protein concentration was measured using the Pierce BCA reagent (Thermo Fisher Scientific, Inc.). Proteins $(50 \mu \mathrm{g})$ were separated using $8-12 \%$ sodium dodecyl sulfate-polyacrylamide 
gel electrophoresis and transferred onto polyvinylidene difluoride membranes (Thermo Fisher Scientific, Inc.). Membranes were blocked with $5 \%$ bovine serum albumin for $1 \mathrm{~h}$ at $37^{\circ} \mathrm{C}$ and incubated with anti-TLR4 (catalog no. sc-10741; dilution, 1:500), anti-MyD88 (catalog no. sc-11356; dilution, 1:500), anti-nuclear

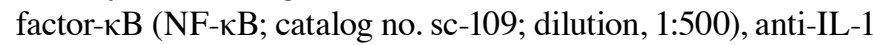
receptor associated kinase (IRAK1; catalog no. sc-7883; dilution, 1:500), anti-p-CREB (catalog no. sc-101663; catalog no. 1:500) and anti-glyceraldehyde 3-phosphate dehydrogenase (GADPH; catalog no. sc-25778; dilution 1:500) (all Santa Cruz Biotechnology, Inc., Dallas, TX, USA) at $4^{\circ} \mathrm{C}$ overnight. A goat anti-rabbit IgG horseradish peroxidase-conjugated secondary antibody (sc-2004; 1:5,000; Santa Cruz Biotechnology, Inc.) was used to incubate the membranes for $1 \mathrm{~h}$ at $37^{\circ} \mathrm{C}$, and a Novex ECL Chemiluminescent Substrate reagent kit (WP20005; Thermo Fisher Scientific, Inc.) was used to visualize the signal bands. Signal bands were acquired using the ChemiDoc XRS ${ }^{+}$ imaging system (Bio-Rad Laboratories, Inc.).

Immunocytofluorescence. $\mathrm{N} 2 \mathrm{~A}$ cells $\left(1-2 \times 10^{4}\right.$ cells $\left./ \mathrm{ml}\right)$ were seeded at cell chamber slides and fixed with $4 \%$ formaldehyde at $4^{\circ} \mathrm{C}$ for $15 \mathrm{~min}$. Next, the cells were blocked with $5 \% \mathrm{BSA}$ assay in phosphate-buffered saline (PBS) for $1 \mathrm{~h}$ at $37^{\circ} \mathrm{C}$ and stained with anti-TLR4 antibody (dilution, 1:100; catalog no. sc-10741; Santa Cruz Biotechnology, Inc.) at $4^{\circ} \mathrm{C}$ overnight. The cells were incubated with appropriate fluorescent secondary antibodies (dilution, 1:500; catalog no. sc-362272; Santa Cruz Biotechnology, Inc.) at room temperature for $1 \mathrm{~h}$ and then stained by DAPI assay at room temperature for 15 min. Cell images were obtained using an FV300 confocal microscope (Olympus Corporation, Tokyo, Japan).

Statistical analysis. All data are expressed as the mean \pm standard error of mean. SPSS 17.0 software was used (IBM,Armonk, NY, USA). Two groups were compared using Student's t-test. Differences among groups were compared using one-way analysis of variance followed by Tukey's post-hoc test. $\mathrm{P}<0.05$ was considered to indicate a statistically significant difference.

\section{Results}

Serum miR-497 expression in patients with cerebral infarction. The serum microRNA-497 expression of patients with cerebral infarction was first determined in the present study. miR-497 expression was upregulated in patients with cerebral infarction compared with that in the healthy volunteers (Fig. 1). This result showed that miR-497 may affect cerebral infarction.

Overexpression of $\mathrm{miR}-497$ induces cell proliferation and decreases apoptosis in N2A cells. Overexpression of miR-497 significantly induced cell proliferation and decreased apoptosis in the cerebral infarction model in vitro compared with the negative group (Fig. 2).

Overexpression of microRNA-497 decreases caspase-3 and caspase-9 activities, and suppresses Bax protein expression in N2A cells. To define the functional role of miR-497 in cerebral infarction, caspase- 3 and caspase- 9 activities were measured using ELISA kits. The overexpression of miR-497 significantly decreased the caspase- 3 and caspase- 9 activities,

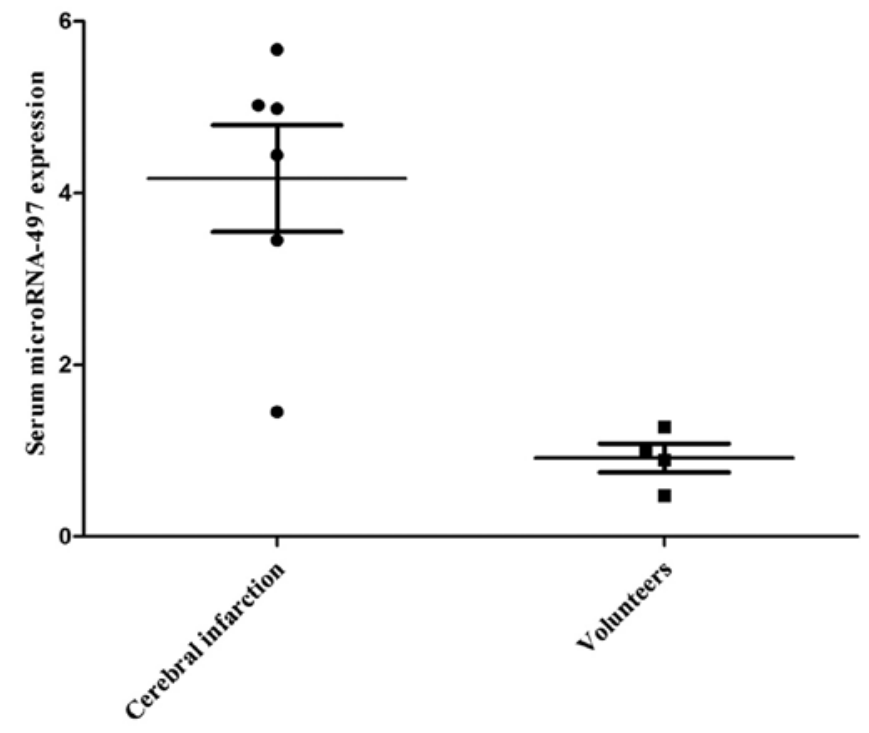

Figure 1. Serum microRNA-497 expression in patients with cerebral infarction.
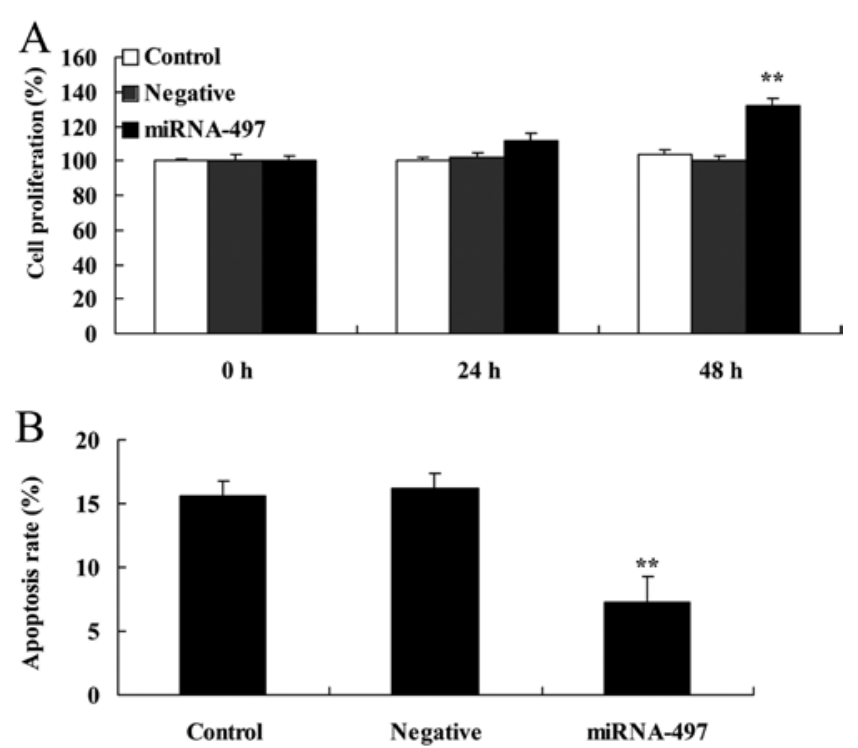

Figure 2. Overexpression of miR-497 induces cell proliferation and decreases apoptosis in N2A cells. Overexpression of miR-497 (A) induced cell proliferation and (B) decreased apoptosis in the N2A cells. ${ }^{* *} \mathrm{P}<0.01$ compared with negative group. $\mathrm{miR} / \mathrm{miRNA}$, microRNA.

and suppressed Bax protein expression in the cerebral infarction model in vitro compared with that in the negative group (Fig. 3).

Overexpression of $\mathrm{miR}-497$ reduces inflammation factors in N2A cells. Next, the effects of miR-497 overexpression on inflammation factors in cerebral infarction were investigated. Compared with the negative group, the miR-497 overexpression group exhibited significantly reduced IL-1 $\beta$, IL-6 and IL-8 levels in the cerebral infarction model in vitro (Fig. 4).

Overexpression of miR-497 suppresses TLR4, MyD88 and $N F-\kappa B$ protein expression in $N 2 A$ cells. To investigate the anti-inflammatory functional role of miR-497 in cerebral infarction, TLR4, MyD88 and NF- $\mathrm{B}$ protein expression was 


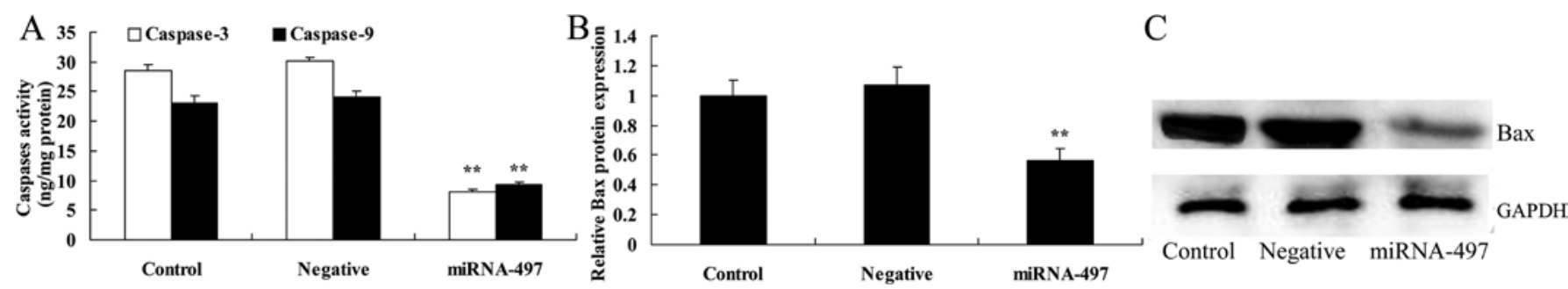

Figure 3. Overexpression of miR-497 decreases caspase-3 and caspase-9 activities, and suppresses Bax protein expression in N2A cells. (A) Decreased caspase-3 and caspase-9 activities, and (B) suppressed Bax protein expression by statistical analysis and (C) western blot assays in N2A cells. ${ }^{* *} \mathrm{P}<0.01$ compared with negative group. miR/miRNA, microRNA; GAPDH, glyceraldehyde 3-phosphate dehydrogenase.
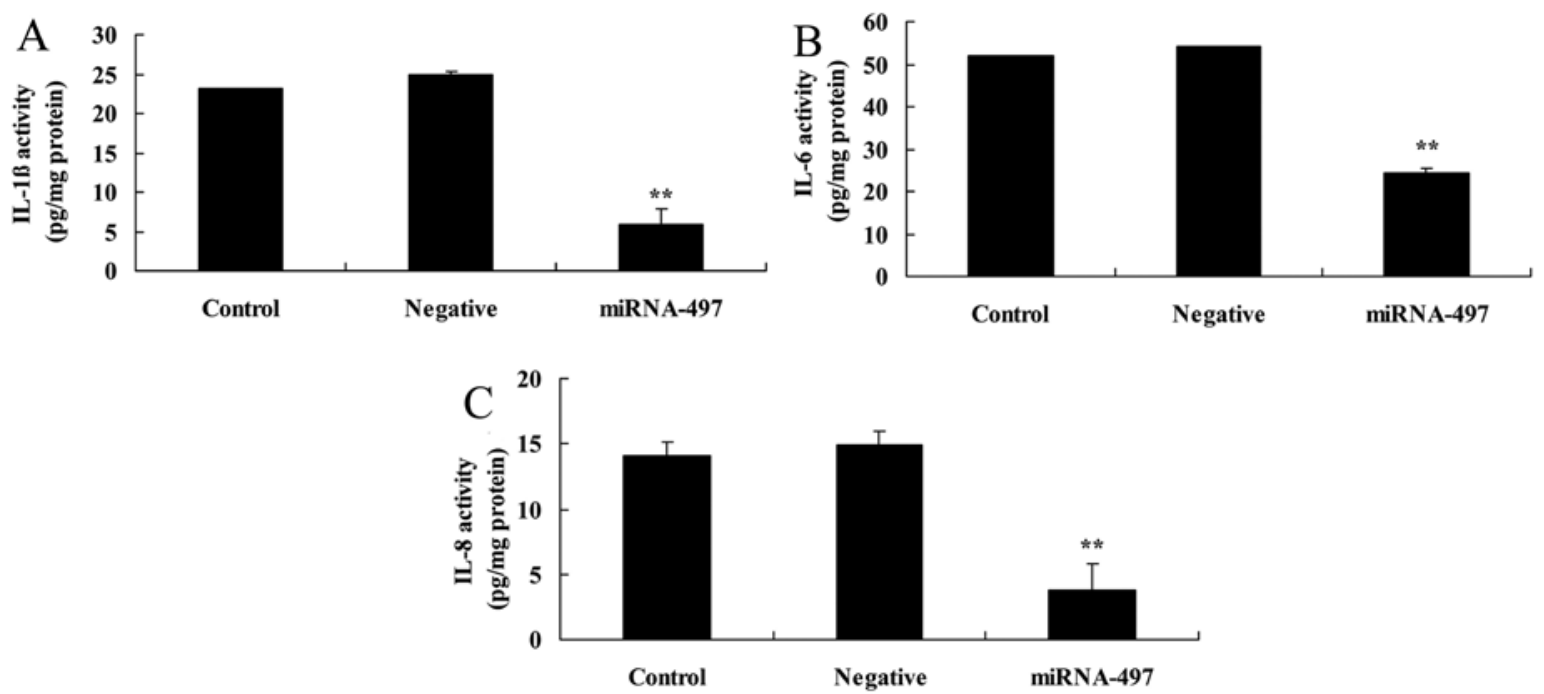

Figure 4. Overexpression of miR-497 reduces inflammation factors in N2A cells. Overexpression of miR-497 reduced (A) IL-1 $\beta$, (B) IL-6 and (C) IL-8 levels in N2A cells. ${ }^{* *} \mathrm{P}<0.01$ compared with negative group. miR/miRNA, microRNA; IL, interleukin.
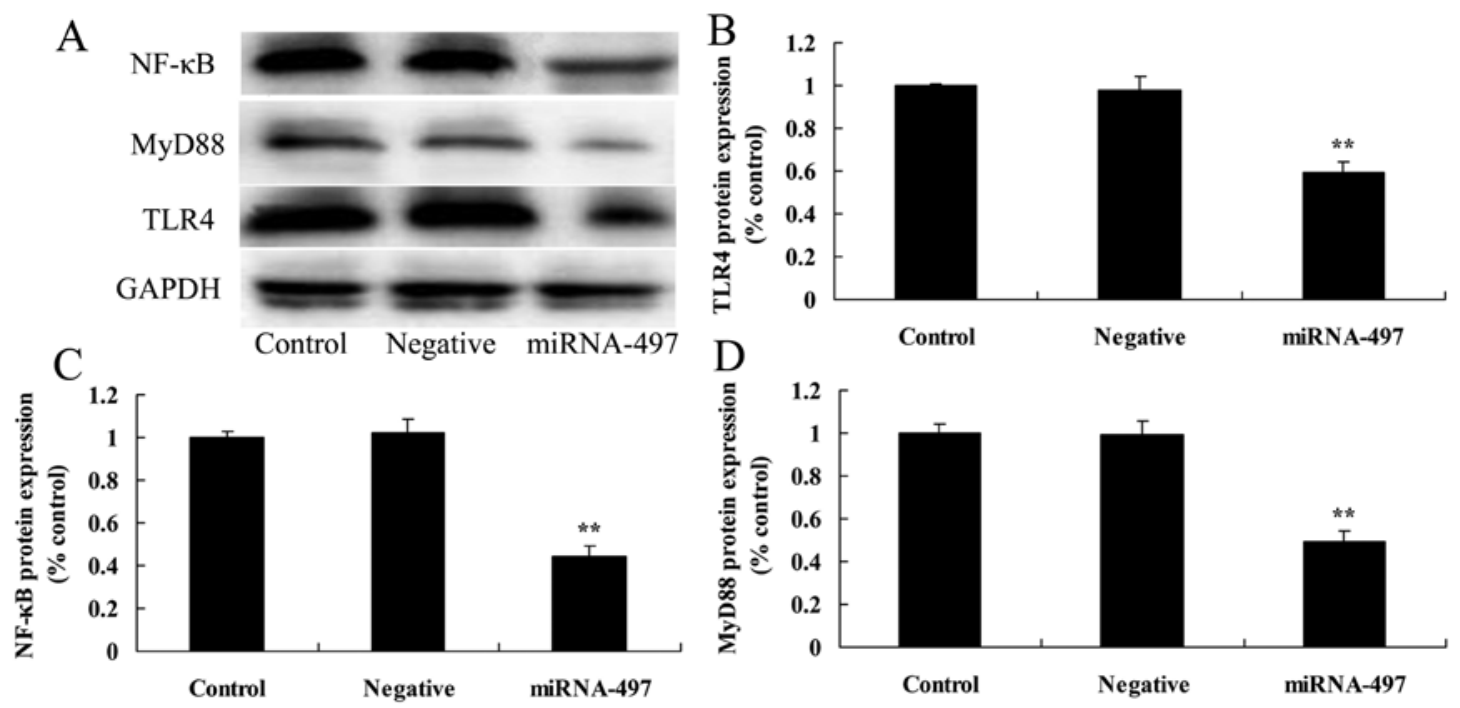

Figure 5. Overexpression of miR-497 suppresses TLR4, MyD88 and NF-kB protein expression in N2A cells. Overexpression of microRNA-497 suppressed TLR4, MyD88 and NF- $\kappa$ B protein expression, as determined using (A) western blot assays and (B-D) statistical analysis in N2A cells. ${ }^{* *} \mathrm{P}<0.01$ compared

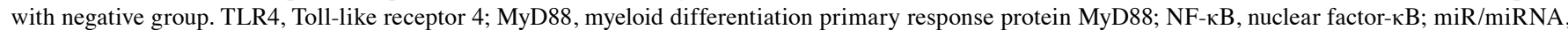
microRNA; GAPDH, glyceraldehyde 3-phosphate dehydrogenase.

measured using western blot analysis. The results of western blot analysis showed that the overexpression of miR-497 significantly suppressed TLR4, MyD88 and NF- $\kappa$ B protein expression in cerebral infarction compared with that in the negative group (Fig. 5).
TLR4 protein expression in N2A cells using immunocytofluorescence. Immunocytofluorescence was used to determine TLR4 protein expression in the N2A cells. As shown in Fig. 6, TLR4 protein expression was significantly suppressed in the 

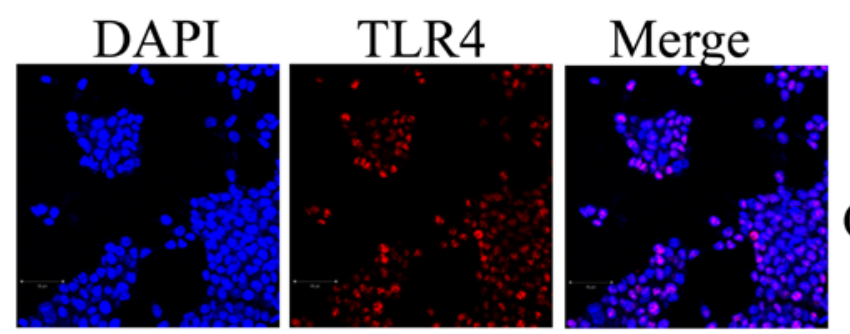

\section{Control}
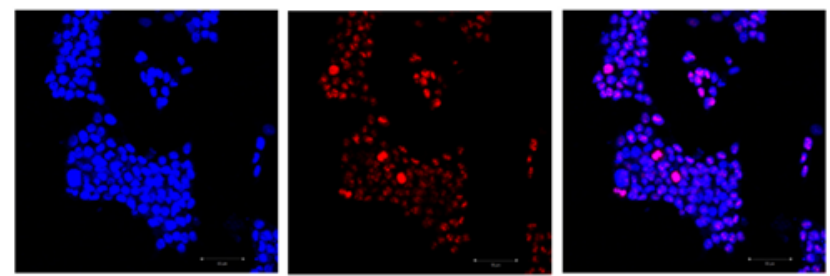

\section{Negative}
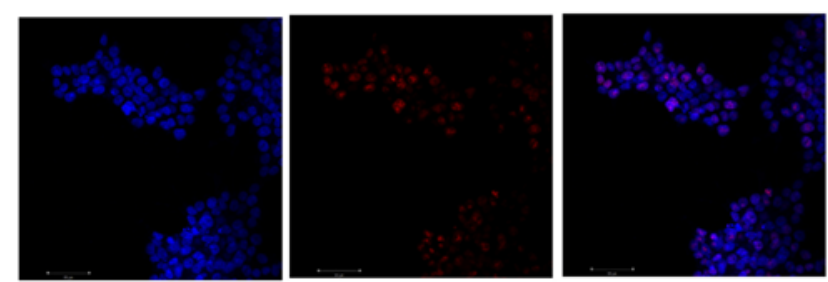

\section{MiRNA-497}

Figure 6. TLR4 protein expression in N2A cells using immunocytofluorescence (magnification, x10). TLR4, Toll-like receptor 4; miRNA, microRNA.
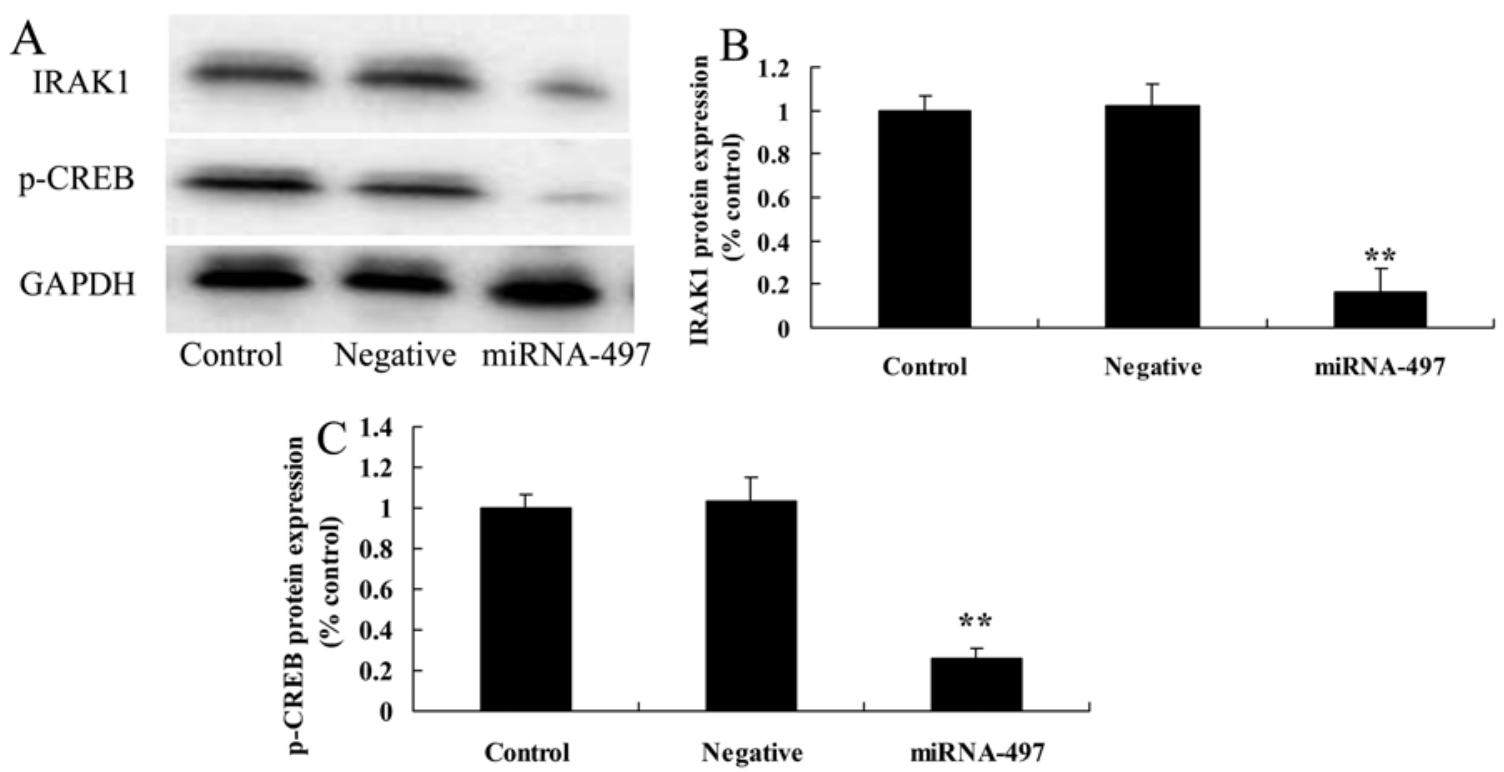

Figure 7. Overexpression of miR-497 suppresses IRAK1 and p-CREB protein expression in N2A cells. Overexpression of miR-497 suppressed IRAK1 and p-CREB protein expression, as determined using (A) western blot assays and (B and C) statistical analysis in N2A cells. "* $\mathrm{P}<0.01$ compared with negative group. IRAK1, IL-1 receptor-associated kinase; CREB, cyclic AMP response element binding protein; p-, phosphorylated; GAPDH, glyceraldehyde 3-phosphate dehydrogenase; miR/miRNA, microRNA.

N2A cells by miR-497 overexpression compared with that in the negative group.

Overexpression of miR-497 suppresses IRAKI and p-CREB protein expression in N2A cells. To determine the anti-inflammatory functional role of miR-497 in cerebral infarction, IRAK1 and p-CREB protein expression was measured using western blot analysis. It was found that miR-497 overexpression significantly suppressed IRAK1 and p-CREB protein expression in cerebral infarction compared with that in the negative group (Fig. 7).
Following miR-497 overexpression, TLR4 inhibitor suppresses TLR4, MyD88 and NF- $\kappa B$ protein expression in N2A cells. The TLR4 inhibitor was used to inhibit TLR4 protein expression in cerebral infarction. As shown in Fig. 7, TLR4 inhibitor significantly suppressed TLR4, MyD88 and NF- $\mathrm{kB}$ protein expression in the N2A cells following miR-497 overexpression compared with that in the miR-497 overexpression group (Fig. 8).

Following miR-497 overexpression, TLR4 inhibitor suppresses inflammation factors in N2A cells. Next, it was determined 

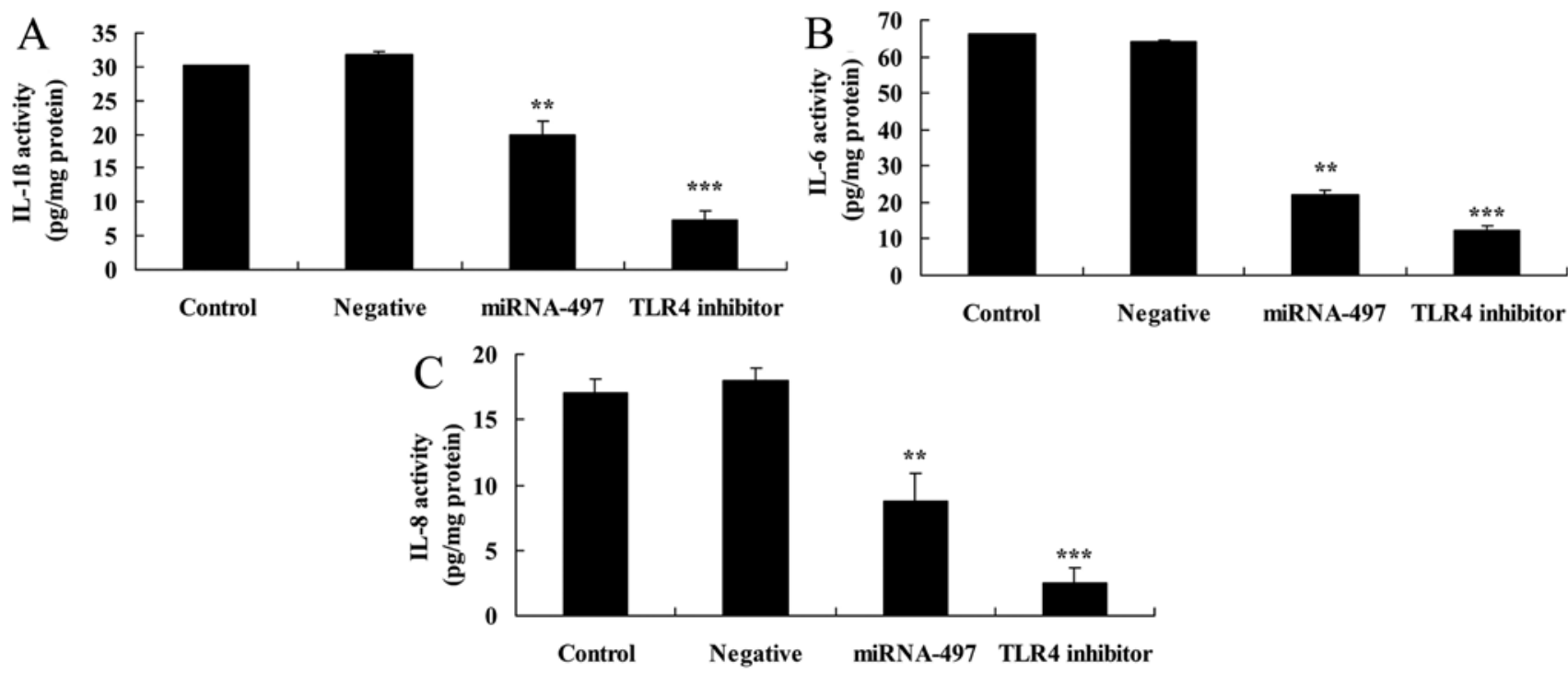

Figure 8. Following miR-497 overexpression, TLR4 inhibitor suppresses inflammation factors in N2A cells. Following miR-497 overexpression, TLR4 inhibitor suppressed (A) IL-1 $\beta$, (B) IL-6 and (C) IL-8 levels in the N2A cells. ${ }^{* * *} \mathrm{P}<0.01$ compared with negative group; ${ }^{* * * *} \mathrm{P}<0.01$ compared with miR-497 overexpression group. TLR4, Toll-like receptor 4; IL, interleukin; miR/miRNA, microRNA.

A
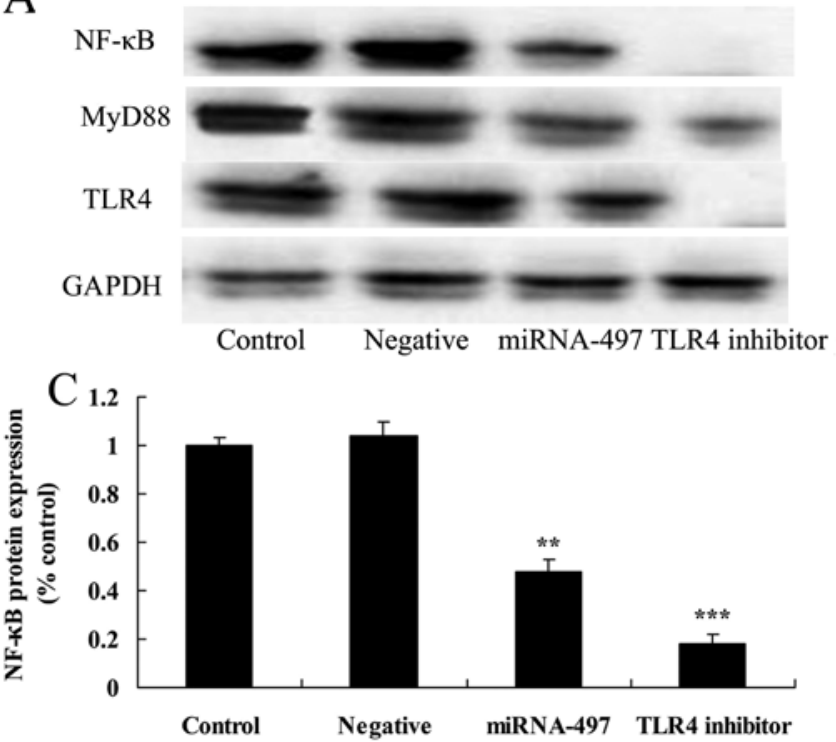

B

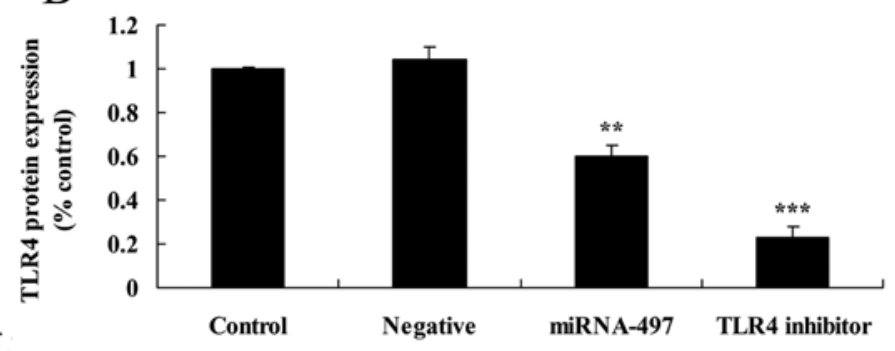

$\mathrm{D}$

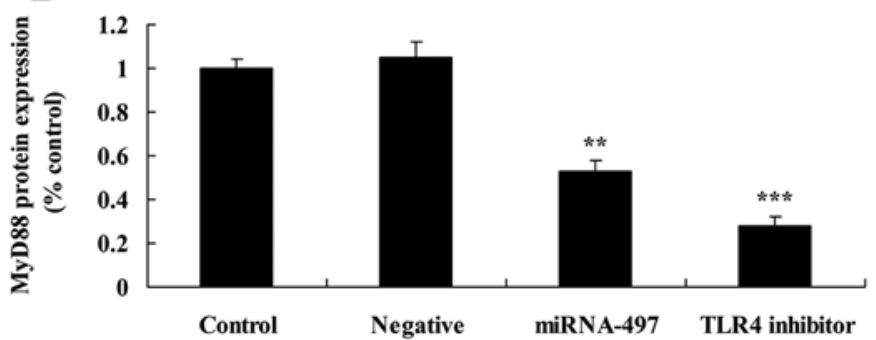

Figure 9. Following miR-497 overexpression, TLR4 inhibitor suppresses TLR4, MyD88 and NF- $\mathrm{B}$ protein expression in N2A cells. Following miR-497 overexpression, TLR4 inhibitor suppressed TLR4, MyD88 and NF- $\kappa$ B protein expression, as determined using (A) western blot assays and (B-D) statistical analysis in N2A cells. ${ }^{* *} \mathrm{P}<0.01$ compared with negative group; ${ }^{* * * *} \mathrm{P}<0.01$ compared with miR-497 overexpression group. TLR4, Toll-like receptor 4; NF- $\kappa \mathrm{B}$, nuclear factor- $\kappa \mathrm{B}$; miR/miRNA, microRNA; MyD88, myeloid differentiation primary response protein MyD88; GAPDH, glyceraldehyde 3-phosphate dehydrogenase.

whether TLR4 inhibitor influences inflammation factors in N2A cells following miR-497 overexpression. Compared with miR-497 overexpression alone, the TLR4 inhibitor significantly suppressed IL-1 $\beta$, IL- 6 and IL- 8 levels in the N2A cells following miR-497 overexpression (Fig. 9).

Following miR-497 overexpression, TLR4 inhibitor suppresses IRAK1 and p-CREB protein expression in N2A cells. The effects of TLR4 inhibitor on IRAK1 and p-CREB protein expression in N2A cells were assessed. Results indicated that TLR4 inhibitor significantly suppressed IRAK1 and p-CREB protein expression in the N2A cells following miR-497 overexpression compared with that in the miR-497 overexpression group (Fig. 10).
Following miR-497 overexpression, CREB inhibitor suppresses IRAK1 and p-CREB protein expression in N2A cells. For western blot analysis, CREB inhibitor was used to inhibit CREB protein expression in cerebral infarction. As shown in Fig. 11, CREB inhibitor was able to inhibit Bax, IRAK1 and p-CREB protein expression in N2A cells following miR-497 overexpression compared with that in the miR-497 overexpression group (Fig. 11).

Following miR-497 overexpression, CREB inhibitor induces cell proliferation and decreases apoptosis in N2A cells. Next, the role of CREB in the effects of miR-497 on cell proliferation and apoptosis in N2A cells following miR-497 overexpression was determined. CREB inhibitor induced 
A

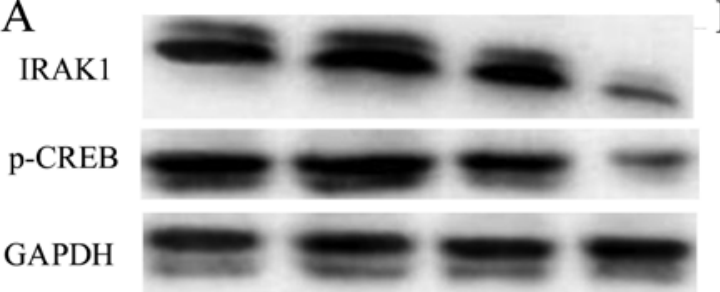

Control Negative miRNA-497 TLR4 inhibitor
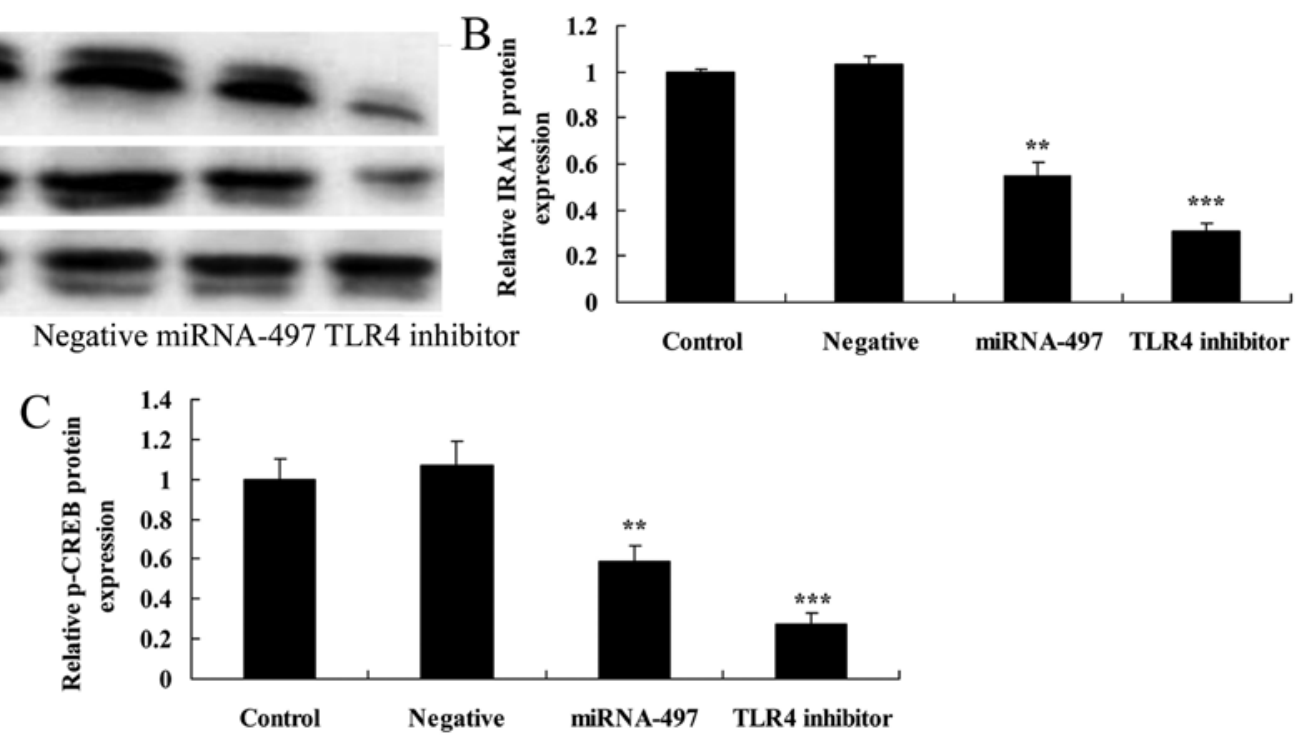

Figure 10. Following miR-497 overexpression, TLR4 inhibitor suppresses IRAK1 and p-CREB protein expression in N2A cells. Following miR-497 overexpression, TLR4 inhibitor suppressed IRAK1 and p-CREB protein expression, as determined using (A) western blot assays and (B and C) statistical analysis in the N2A cells. ${ }^{* *} \mathrm{P}<0.01$ compared with negative group; ${ }^{* * *} \mathrm{P}<0.01$ compared with miR-497 overexpression group. IRAK1, IL-1 receptor-associated kinase; CREB, cyclic AMP response element binding protein; p-, phosphorylated; GAPDH, glyceraldehyde 3-phosphate dehydrogenase; miR/miRNA, microRNA.

A

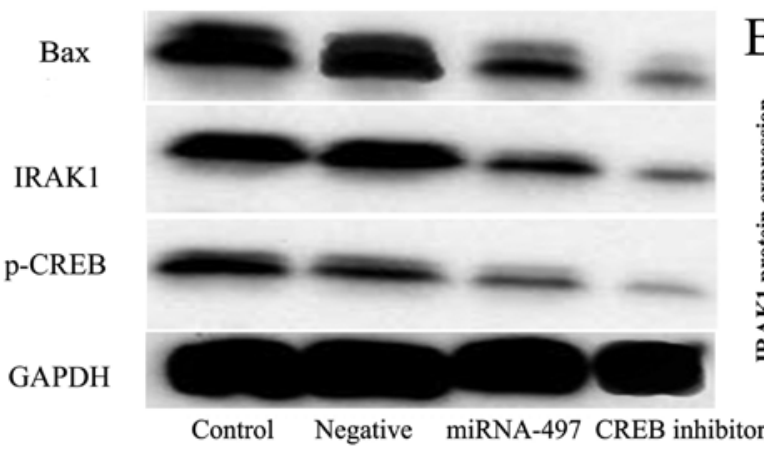

$\mathrm{B}$

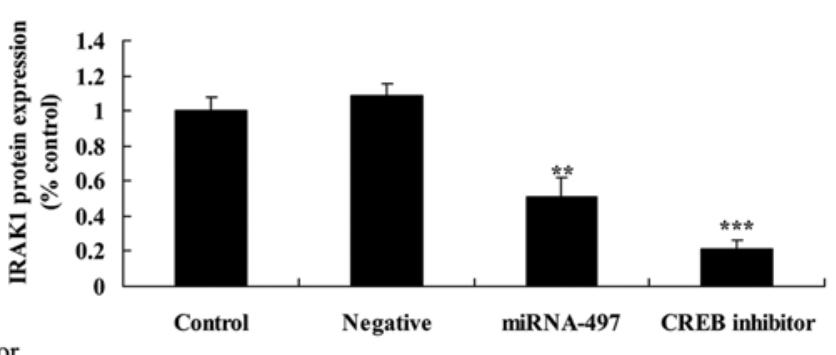

C

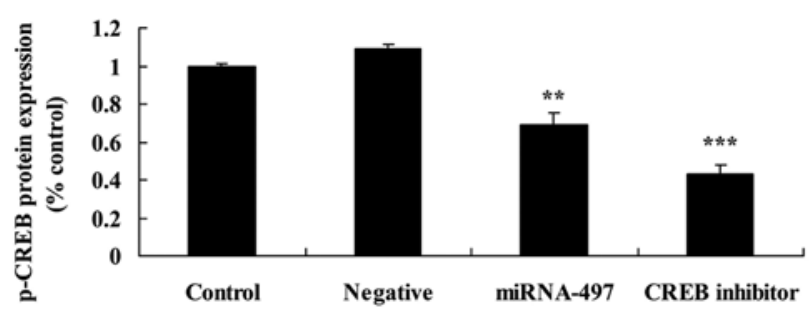

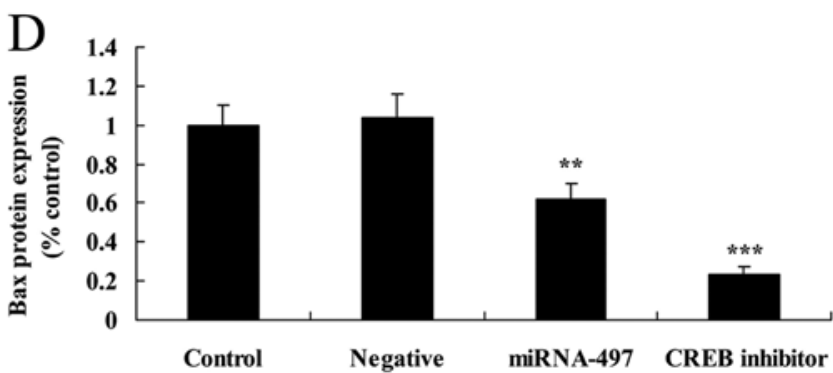

Figure 11. Following miR-497 overexpression, CREB inhibitor suppresses IRAK1, p-CREB and Bax protein expression in N2A cells. Following miR-497 overexpression, CREB inhibitor suppressed IRAK1, p-CREB and Bax protein expression, as determined using (A) western blot assays and (B-D) statistical analysis in the N2A cells. ${ }^{* *} \mathrm{P}<0.01$ compared with negative group, ${ }^{* * *} \mathrm{P}<0.01$ compared with miR-497 overexpression group. IRAK1, IL-1 receptor-associated kinase; CREB, cyclic AMP response element binding protein; p-, phosphorylated; GAPDH, glyceraldehyde 3-phosphate dehydrogenase; miR/miRNA, microRNA.

cell proliferation and decreased apoptosis in the N2A cells following miR-497 overexpression compared with that in the miR-497 overexpression group (Fig. 12).

Following microRNA-497 overexpression, CREB inhibitor decreases caspase-3 and caspase-9 activities, and suppresses Bax protein expression in N2A cells. Fig. 13 showed that following miR-497 overexpression, CREB inhibitor decreased caspase- 3 and caspase- 9 activities in the N2A cells compared with that in the miR-497 overexpression group.

\section{Discussion}

A large amount of the experimental research data from the middle cerebral arterial embolism models verify that inflammatory cell adhesion molecules, chemokines and cytokines serve key roles in cell apoptosis following focal cerebral ischemia reperfusion injury (18). Investigating the mechanism of the focal cerebral ischemia reperfusion injury can directly instruct some drugs, with anti-inflammation and anti-apoptosis being the targets used in the clinic to treat and intervene in strokes (19). 

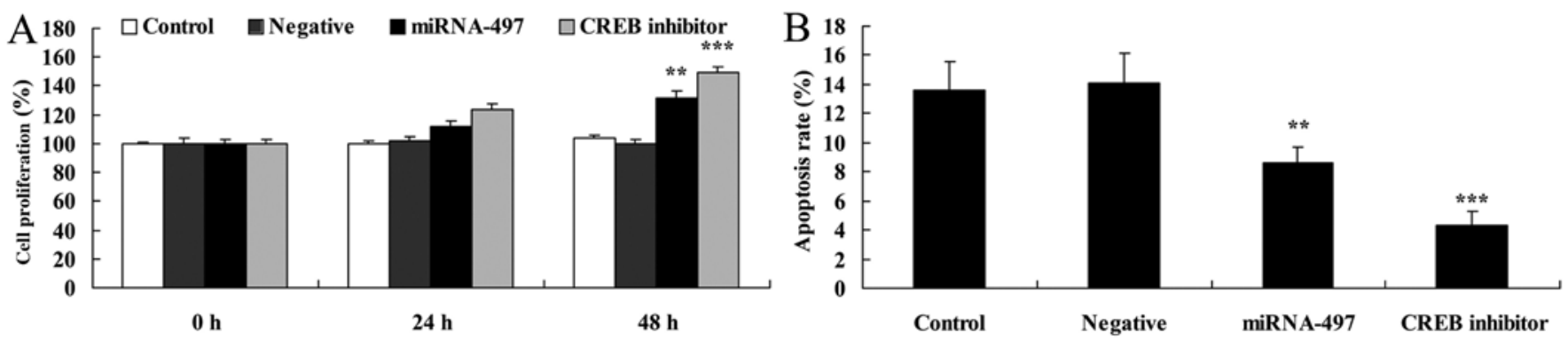

Figure 12. Following miR-497 overexpression, CREB inhibitor induces cell proliferation and decreases apoptosis in N2A cells. Following miR-497 overexpression, CREB inhibitor induced (A) cell proliferation and (B) decreased apoptosis in the N2A cells. ${ }^{* *} \mathrm{P}<0.01$ compared with negative group; ${ }^{* * * *} \mathrm{P}<0.01$ compared with miR-497 overexpression group. CREB, cyclic AMP response element binding protein; miR/miRNA, microRNA.

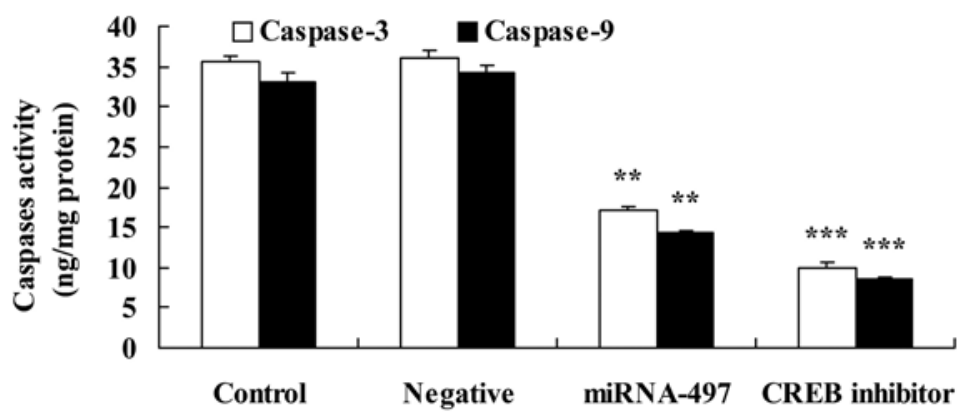

Figure 13. Following miR-497 overexpression, CREB inhibitor decreases caspase-3 and caspase-9 activities in N2A cells. Following miR-497 overexpression, CREB inhibitor decreased caspase-3 and caspase-9 activities in the N2A cells. ${ }^{* *} \mathrm{P}<0.01$ compared with negative group; ${ }^{* * * *} \mathrm{P}<0.01$ compared with miR-497 overexpression group. CREB, cyclic AMP response element binding protein; miR/miRNA, microRNA.

The present results indicated that serum miR-497 expression in patients with cerebral infarction was upregulated compared with that in healthy volunteers. Furthermore, it was also demonstrated that overexpression of miR-497 significantly induced cell proliferation, decreased apoptosis, and reduced IL-1 $\beta$, IL- 6 and IL-8 levels in the cerebral infarction model in vitro. Li et al (20) demonstrated that inhibition of miR-497 ameliorates anoxia/ reoxygenation injury in cardiomyocytes by suppressing cell apoptosis.

TLR is also extensively expressed in the central nervous system, and is mainly distributed in the neuroglial cells, including microglia, astrocytes and oligodendrocytes (21). The excessive inflammatory response in the brain tissue following focal cerebral ischemia reperfusion is one of the important mechanisms leading to reperfusion injury, which requires the infiltration of inflammatory cells and the involvement of certain cytokines, intercellular adhesion molecules and chemokines (22). TLR has been found to serve an important role in the inflammatory response following focal cerebral ischemia reperfusion. In the cerebral ischemic response, TLR may induce the occurrence of the inflammatory response through identifying the endogenous ligands released in the cerebral ischemic injury (23). The mechanism of action of TLR in cerebral ischemia has become a research focus in recent years, and currently, TLR2, TLR, TLR9 and particularly TLR4 have a relatively well-established association with cerebral ischemia (22). The present study next examined the significant suppression of TLR4, MyD88 and $\mathrm{NF}-\kappa \mathrm{B}$ protein expression in cerebral infarction following the overexpression of miR-497. Xu et al (24) demonstrated that miR-497 could inhibit the inflammation and apoptosis of spinal cord ischemia-reperfusion injury through IRAK1 of TLR4 and the CREB signaling pathway.

Once the TLR4 system is activated, it can activate the expression of $\mathrm{NF}-\kappa \mathrm{B}$ through the MyD88-dependent and MyD88-independent signal pathways, and thus mediate the upregulation of certain inflammatory response factors, including tumor necrosis factor- $\alpha$ (TNF- $\alpha)$ and IL-1 $(13,14)$. It has been demonstrated by research that the innate immune response and the inflammatory response serve a fairly important role in focal cerebral ischemia reperfusion injury (14). The present results indicated that TLR4 inhibitor suppressed inflammation factors in N2A cells following miR-497 overexpression. Kong et al (25) reported that miR-497 may exhibit an anticancer function by regulating the $N F-\kappa B$ signaling pathway in human prostate cancer cells.

The transient ischemia of brain tissue will lead to cerebral ischemic injury, while the inflammatory response following the restoration of the brain blood supply will cause a second brain injury, known as an ischemia reperfusion injury (26). The latest research suggests that the innate immune response and the inflammatory response serve extremely critical roles in focal cerebral ischemia reperfusion injury (27). As an important nuclear transcription factor, $\mathrm{NF}-\kappa \mathrm{B}$ mediates the synthesis of certain genes, such as TNF- $\alpha$, and it is closely associated with the immuno-inflammatory response following focal cerebral ischemia reperfusion injury (28). Numerous studies have confirmed that puerarin can protect against the inflammatory response injury following focal cerebral ischemia reperfusion injury through the inhibition of $N F-\kappa B$ activity and the reduction in TNF- $\alpha$ expression $(14,29)$. These present results 
indicated that TLR4 inhibitor suppressed TLR4, MyD88 and $\mathrm{NF}-\kappa \mathrm{B}$ protein expression, and reduced IRAK1 and $\mathrm{p}-\mathrm{CREB}$ protein expression in the N2A cells following miR-497 overexpression.

The TLR4-TIRAP-MyD88 signal pathway can take part in the phagocytosis and degradation of amyloid $\beta$ in the early stage of Alzheimer's disease (AD), and can reduce its deposition, but the release of its subsequent activated inflammatory factors will cause neuronal apoptosis and accelerate the course of AD (30). In addition, research on mouse and human atherosclerosis has shown that TLR4 is closely associated with the development of atherosclerosis (26). The intense activation of the TLR4-TIRAP-MyD88 signaling pathway will result in the secretion of a high level of inflammatory cytokines, and will accelerate plaque formation and development (12). The present results showed that miR-497 overexpression significantly suppressed IRAK1 and p-CREB protein expression in cerebral infarction in N2A cells following miR-497 overexpression.

Extracellular signal-regulated kinase (ERK) is a member of the MAPK sub-family, which will be phosphorylated when upstream mitogen-activated protein kinase kinase is intensively stimulated by the calcium influx of the N-methyl-D-aspartate receptor calcium channel within the synapse (31). p-ERK has an essential role in regulating neuronal survival during the pathological stage of stroke, and inhibits the activation of the associated pro-apoptotic molecular mechanisms (32). The activated ERK develops nuclear translocation and phosphorylates the downstream CREB through the p90 ribosomal S6 kinase (31). p-CREB regulates the expression of the Bcl-2, $\mathrm{C}$-fos and BDNF genes, promotes the expression of the antioxidant enzyme and anti-apoptotic protein, enhances ischemia tolerance and reduces delayed neuronal death $(29,32)$. The present results demonstrated that CREB inhibitor suppressed p-CREB protein expression, induced cell proliferation, decreased apoptosis and caspase- 3 and caspase- 9 activities, and suppressed Bax protein expression in N2A cells following miR-497 overexpression. Xu et al (24) demonstrated that miR-497 could inhibit the inflammation and apoptosis of spinal cord ischemia-reperfusion injury through IRAK1 of the TLR4 and CREB signaling pathways.

In conclusion, the present study data demonstrated that miR-497 attenuated cerebral infarction in patients through anti-inflammation and anti-apoptosis mechanisms by regulating the TLR4 and CREB signaling pathways. Furthermore, miR-497/ TLR4 and CREB signaling pathways may have an impact on the molecular target spot of cerebral infarction patients in the future.

\section{Acknowledgements}

Not applicable.

\section{Funding}

No funding was received.

\section{Availability of data and material}

The analyzed datasets generated during the study are available from the corresponding author on reasonable request.

\section{Authors' contributions}

SC designed the experiment. WY, KB and BL performed the experiment. SC analyzed the data and wrote the manuscript. All authors read and approved the final manuscript.

\section{Ethics approval and consent to participate}

All patients provided written informed consent and the study was approved by the Medical Ethics Committee of Tangshan Worker Hospital.

\section{Consent for publication}

Not applicable.

\section{Competing interests}

The authors declare that they have no competing interests.

\section{References}

1. Thangarajh M, Yang G, Fuchs D, Ponisio MR, McKinstry RC, Jaju A, Noetzel MJ, Casella JF, Barron-Casella E, Hooper WC, et al: Magnetic resonance angiography-defined intracranial vasculopathy is associated with silent cerebral infarcts and glucose-6-phosphate dehydrogenase mutation in children with sickle cell anaemia. Br J Haematol 159: 352-359, 2012.

2. Su Y, Fan L, Zhang Y, Zhang Y, Ye H, Gao D, Chen W and Liu G: Improved Neurological Outcome With Mild Hypothermia in Surviving Patients With Massive Cerebral Hemispheric Infarction. Stroke 47: 457-463, 2016.

3. Taomoto K, Ohnishi H, Kuga Y, Nakashima K, Ichioka T, Kodama Y, Kubota H, Tominaga T, Hirose T, Hayashi M, et al: Platelet function and spontaneous thrombolytic activity of patients with cerebral infarction assessed by the global thrombosis test. Pathophysiol Haemost Thromb 37: 43-48, 2010.

4. Miwa K, Tanaka M, Okazaki S, Furukado S, Sakaguchi M and Kitagawa K: Relations of blood inflammatory marker levels with cerebral microbleeds. Stroke 42: 3202-3206, 2011.

5. Zhan J, Qin W, Zhang Y, Jiang J, Ma H, Li Q and Luo Y: Upregulation of neuronal zinc finger protein A20 expression is required for electroacupuncture to attenuate the cerebral inflammatory injury mediated by the nuclear factor-kB signaling pathway in cerebral ischemia/reperfusion rats. J Neuroinflammation 13: 258, 2016.

6. Sarajärvi T, Lipsanen A, Mäkinen P, Peräniemi S, Soininen H, Haapasalo A, Jolkkonen J and Hiltunen M: Bepridil decreases A $\beta$ and calcium levels in the thalamus after middle cerebral artery occlusion in rats. J Cell Mol Med 16: 2754-2767, 2012.

7. Du R, Teng JF, Wang Y, Zhao XY and Shi ZB: Clinical study of Butylphthalide combined with Xue Shuan Tong on serum inflammatory factors and prognosis effect of patients with cerebral infarction. Pak J Pharm Sci 28 (Suppl 5): 1823-1827, 2015.

8. Kim SJ, Shin HY, Ha YS, Kim JW, Kang KW, Na DL and Bang OY: Paradoxical embolism as a cause of silent brain infarctions in healthy subjects: The ICONS study (Identification of the Cause of Silent Cerebral Infarction in Healthy Subjects). Eur J Neurol 20: 353-360, 2013.

9. Zhang J, Yuan L, Zhang X, Hamblin MH, Zhu T, Meng F, Li Y, Chen YE and Yin KJ: Altered long non-coding RNA transcriptomic profiles in brain microvascular endothelium after cerebral ischemia. Exp Neurol 277: 162-170, 2016.

10. Liu XS, Chopp M, Zhang RL and Zhang ZG: MicroRNAs in cerebral ischemia-induced neurogenesis. J Neuropathol Exp Neurol 72: 718-722, 2013.

11. Eklind S, Mallard C, Leverin AL, Gilland E, Blomgren K, Mattsby-Baltzer I and Hagberg H: Bacterial endotoxin sensitizes the immature brain to hypoxic--ischaemic injury. Eur $\mathbf{J}$ Neurosci 13: 1101-1106, 2001. 
12. Fan H, Li L, Zhang X, Liu Y, Yang C, Yang Y and Yin J: Oxymatrine downregulates TLR4, TLR2, MyD88, and NF-kappaB and protects rat brains against focal ischemia. Mediators Inflamm 2009: 704706, 2009.

13. Li Y, Xu XL, Zhao D, Pan LN, Huang CW, Guo LJ, Lu Q and Wang J: TLR3 ligand poly IC attenuates reactive astrogliosis and improves recovery of rats after focal cerebral ischemia. CNS Neurosci Ther 21: 905-913, 2015.

14. Belinga VF, Wu GJ, Yan FL and Limbenga EA: Splenectomy following MCAO inhibits the TLR4-NF- $\mathrm{BB}$ signaling pathway and protects the brain from neurodegeneration in rats. J Neuroimmunol 293: 105-113, 2016.

15. Lin R, Lin Y, Tao J, Chen B, Yu K, Chen J, Li X and Chen LD: Electroacupuncture ameliorates learning and memory in rats with cerebral ischemia-reperfusion injury by inhibiting oxidative stress and promoting p-CREB expression in the hippocampus. Mol Med Rep 12: 6807-6814, 2015.

16. Bell KF, Bent RJ, Meese-Tamuri S, Ali A, Forder JP and Aarts MM: Calmodulin kinase IV-dependent CREB activation is required for neuroprotection via NMDA receptor-PSD95 disruption. J Neurochem 126: 274-287, 2013.

17. Livak KJ and Schmittgen TD: Analysis of relative gene expression data using real-time quantitative PCR and the 2(-Delta Delta C(T)) method. Methods 25: 402-408, 2001.

18. Ferguson S and Macdonald RL: Predictors of cerebral infarction in patients with aneurysmal subarachnoid hemorrhage. Neurosurgery 60: 658-667, 2007.

19. Ueno H, Koyama H, Mima Y, Fukumoto S, Tanaka S, Shoji T, Emoto M, Shoji T, Nishizawa Y and Inaba M: Comparison of the effect of cilostazol with aspirin on circulating endothelial progenitor cells and small-dense LDL cholesterol in diabetic patients with cerebral ischemia: A randomized controlled pilot trial. J Atheroscler Thromb 18: 883-890, 2011.

20. Li X, Zeng Z, Li Q, Xu Q, Xie J, Hao H, Luo G, Liao W, Bin J, Huang X, et al: Inhibition of microRNA-497 ameliorates anoxia/ reoxygenation injury in cardiomyocytes by suppressing cell apoptosis and enhancing autophagy. Oncotarget 6: 18829-18844, 2015.

21. Caso JR, Pradillo JM, Hurtado O, Lorenzo P, Moro MA and Lizasoain I: Toll-like receptor 4 is involved in brain damage and inflammation after experimental stroke. Circulation 115: 1599-1608, 2007.

22. Cao CX, Yang QW, Lv FL, Cui J, Fu HB and Wang JZ: Reduced cerebral ischemia-reperfusion injury in Toll-like receptor 4 deficient mice. Biochem Biophys Res Commun 353: 509-514, 2007.
23. Wang Y, Ge P and Zhu Y: TLR2 and TLR4 in the brain injury caused by cerebral ischemia and reperfusion. Mediators Inflamm 2013: 124614, 2013.

24. Xu M, Wang HF, Zhang YY and Zhuang HW: Protection of rats spinal cord ischemia-reperfusion injury by inhibition of miR-497 on inflammation and apoptosis: Possible role in pediatrics. Biomed Pharmacother 81: 337-344, 2016.

25. Kong XJ, Duan LJ, Qian XQ, Xu D, Liu HL, Zhu YJ and Qi J: Tumor-suppressive microRNA-497 targets IKK $\beta$ to regulate $\mathrm{NF}-\kappa \mathrm{B}$ signaling pathway in human prostate cancer cells. Am J Cancer Res 5: 1795-1804, 2015.

26. Kunz A, Abe T, Hochrainer K, Shimamura M, Anrather J, Racchumi G, Zhou P and Iadecola C: Nuclear factor-kappaB activation and postischemic inflammation are suppressed in CD36-null mice after middle cerebral artery occlusion. J Neurosci 28: 1649-1658, 2008.

27. Xie W, Fang L, Gan S and Xuan H: Interleukin-19 alleviates brain injury by anti-inflammatory effects in a mice model of focal cerebral ischemia. Brain Res 1650: 172-177, 2016.

28. Zhu XC, Jiang T, Zhang QQ, Cao L, Tan MS, Wang HF, Ding ZZ, Tan L and Yu JT: Chronic Metformin Preconditioning provides neuroprotection via suppression of NF- $\kappa \mathrm{B}$-mediated inflammatory pathway in rats with permanent cerebral ischemia. Mol Neurobiol 52: 375-385, 2015

29. Zhang X, Zhang X, Wang C, Li Y, Dong L, Cui L, Wang L, Liu Z, Qiao H, Zhu C, et al: Neuroprotection of early and short-time applying berberine in the acute phase of cerebral ischemia: Upregulated pAkt, pGSK and pCREB, downregulated NF- $\kappa \mathrm{B}$ expression, ameliorated BBB permeability. Brain Res 1459: 61-70, 2012

30. Qiao H, Zhang X, Zhu C, Dong L, Wang L, Zhang X, Xing Y, Wang C, Ji Y and Cao X: Luteolin downregulates TLR4, TLR5, $\mathrm{NF}-\kappa \mathrm{B}$ and $\mathrm{p}$-p38MAPK expression, upregulates the p-ERK expression, and protects rat brains against focal ischemia. Brain Res 1448: 71-81, 2012

31. Choi IY, Ju C, Anthony Jalin AM, Lee DI, Prather PL and Kim WK: Activation of cannabinoid CB2 receptor-mediated AMPK/CREB pathway reduces cerebral ischemic injury. Am J Pathol 182: 928-939, 2013.

32. Cheng CY, Tang NY, Kao ST and Hsieh CL: Ferulic acid administered at various time points protects against cerebral infarction by activating p38 MAPK/p90RSK/CREB/Bcl-2 anti-apoptotic signaling in the subacute phase of cerebral ischemia-reperfusion injury in rats. PLoS One 11: e0155748, 2016. 